\title{
Discrete Element Modelling (DEM) of hemp processing using a hammermill
}

\author{
Mohammad A. Sadek ${ }^{1, *}$ and Ying Chen ${ }^{2}$ \\ ${ }^{1}$ BioResource and Agricultural Engineering Department, California Polytechnic State University, San Luis Obispo, CA, USA \\ ${ }^{2}$ Department of Biosystems Engineering, University of Manitoba, Winnipeg, MB, R3T 5 V6 Canada.
}

Corresponding Author: mosadek@calpoly.edu

\begin{abstract}
The discrete element method (DEM) was used to develop a model to simulate hemp processing using a hammer mill. The model was computed using a commercial software package - Particle Flow Code in Three Dimensions ( $\left.\mathrm{PFC}^{3 \mathrm{D}}\right)$. In the model, a simulated hemp stem was defined using spherical particles connected with parallel bonds implemented in the $\mathrm{PFC}^{3 \mathrm{D}}$. The breakage of the bonds mimics the hemp breaking phenomenon within the hammermill. A micro property, bond strength of the hemp stems, was calibrated using the literature data from compression tests of hemp stems. The calibrated bond strength was $2.2 \times 10^{6} \mathrm{~Pa}$. With the calibrated bond strength, the model was used to simulate the power and energy distributions within the hammermill. The simulations were performed for different hammer rotational speeds and feeding masses. The results showed that both the specific kinetic and strain energies increased with the increase of the feeding mass; however, the effects of the hammer rotational speed did not follow any particular trends.
\end{abstract}

\section{RÉSUMÉ}

La méthode des éléments discrets (DEM) a été utilisée pour développer un modèle permettant de simuler le traitement du chanvre à l'aide d'un moulin à marteaux. Le modèle a été calculé à l'aide d'un logiciel commercial - Particle Flow Code in Three Dimensions ( $\mathrm{PFC}^{3 \mathrm{D}}$ ). Dans le modèle, une tige de chanvre simulée a été définie à l'aide de particules sphériques reliées par des liens parallèles appliquées dans le $\mathrm{PFC}^{3 \mathrm{D}}$. La rupture des liens imite le phénomène de rupture du chanvre dans le moulin à marteaux. Une micropropriété, la force de liaison des tiges de chanvre, a été calibrée en utilisant les données de la littérature provenant des tests de compression des tiges de chanvre. La force des liens calibrée était de $2,2 \times 10^{6} \mathrm{~Pa}$. Avec cette force calibrée, le modèle a été utilisé pour simuler les distributions de puissance et d'énergie dans le moulin à marteaux. Les simulations ont été effectuées pour différentes vitesses de rotation des marteaux et masses d'alimentation du moulin. Les résultats ont montré que les valeurs d'énergie cinétique et de déformation spécifiques augmentent avec la masse d'alimentation; toutefois, les effets de la vitesse de rotation du marteau ne suivent aucune tendance particulière.

\section{KEYWORDS}

Discrete element method (DEM), $\mathrm{PFC}^{3 \mathrm{D}}$, hammermill, energy, power, hemp.

\section{MOTS CLÉS}

méthode des éléments discrets (DEM), $\mathrm{PFC}^{3 \mathrm{D}}$, moulin à marteaux, énergie, puissance, chanvre.

\section{CITATION}

Sadek, M.A. and Y. Chen. 2021. Discrete element modelling (DEM) of hemp processing using a hammermill. Canadian Biosystems Engineering/Le génie des biosystèmes au Canada 63: 2.1-2.11. https://doi.org/10.7451/CBE.2021.63.2.1 


\section{INTRODUCTION}

Hammermill has been used for processing a wide range of materials because of its high processing capacity, simple design, and versatility. For example, the hammermill is used for biomass size reduction in the forage industry (Shi et al. 2003) and agriculture (Mani et al. 2004; Miao et al. 2011). Hammermill is an energy-intensive machine. Energy consumption of hammermills depends on many factors, including particle size and moisture content of the feed, feeding rate, screen opening, and operational conditions of hammermills (Yu et al. 2006; Lopo 2002; Shi et al. 2003; Vigneault et al. 1992). Djordjevic et al. (2003) reported that the specific energy was independent of particle size at low rotational speeds. The specific energy increases significantly below certain particle sizes but decreases for larger particle sizes with a higher rotational speed. Higher moisture content resulted in higher energy consumption when a hammermill was used for processing biomass (switchgrass, barley, and wheat straw) (Mani et al. 2004; Miao et al. 2011).

Baker (2009) studied hemp processing using a hammermill and reported that larger feed mass required more energy for processing. That study also found that more power was needed to process hemp when using smaller screen openings. Other researchers reported similar results ( $\mathrm{Yu}$ et al. 2006; Savoie et al. 1989). Except for Baker (2009), all those experimental studies concerned materials other than hemp.

During hemp processing using a hammermill, hemp stalk is impacted by highly rotating hammers, breaking hemp stalk into pieces. This dynamic process is complicated, involving particle movement and contact forces between particles and machine parts. These dynamic behaviours are important as they determine the energy requirement of the hammermill. Due to the nonhomogenous nature of hemp material and larger displacement of particles, it is not possible to quantify these dynamic behaviours using analytical methods or other continuous numerical methods such as finite element analysis (FEA). The discrete element method (DEM) is a promising tool to study particle dynamic behaviours like the interaction between hemp particles and rotating hammers. The DEM is a numerical method that models a material as an assemblage of discrete particles. Therefore, the discrete element method (DEM) was used in this study to understand the dynamic behaviours of hemp material impacted by rotating hammers.

The DEM was first introduced by Cundall and Strack (1979) to model the dynamics of the rocks. Since then, DEM has been used in diverse areas, including milling machines, such as ball mill (Guzman et al. 2015; Cleary 1998, 2000; van Nierop et al. 2001; Mishra and Murty 2001), tumbling mill (Djordjevic 2003); SAG mill (Rajamani et al. 2000), centrifugal mill (Inoue and Okaya,1996; Cleary and Hoyer 2000), and impact crusher (Hammermill) (Djordjevic et al. 2003). Little work has been done for the hammermill.
In this study, the DEM method was used to model the interaction of hemp particles and hammermill. The computation of the model was done using the Particle Flow Code in Three Dimensions $\left(\mathrm{PFC}^{3 \mathrm{D}}\right.$ ) (Itasca Consulting Group, Inc., Minneapolis, MN). PFC ${ }^{3 \mathrm{D}}$ works with two major components, Ball and Wall. Balls are spherical, and walls are rectangular, cylindrical, ring, disc, or 3D lines. Assemblies of individual balls represent materials to be simulated. A group of balls can be arranged to simulate any arbitrary shape of particle assembly. Particles in an assembly could be either bonded together or free-flowing. Depending on the nature of the materials to be simulated. A set of microproperties needs to be assigned to the balls and bonds so that the model particles can predict the specific bulk behaviour of simulated behaviour. For homogeneous material, some parameters could be directly measured. In the case of biological material such as hemp, considered heterogeneous material requires additional precaution to measure some intrinsic properties such as stiffness. As DEM is still new for the biological material simulation, those microproperties either need to be determined from the theory or calibrated before the simulation. Fundamental material property tests can be used for calibrations. For example, Franco et al. (2007) and Coetzee and Els (2009) used direct shear tests to calibrate model micro properties of soil through matching simulated friction angles with measured angles of the soil. Sadek et al. (2011) also used direct shear tests in calibrating some micro properties of hemp fibre and core (ground), and those calibrated micro properties were used in the simulations of this study. Additional micro properties required were calibrated in this study using compression tests.

In summary, understanding the interactions between hemp particles and hammermill and among particles is essential to understanding the hammermill's energy consumption. The objectives of the study were to: (a) develop a model to simulate hemp processing with a hammermill using $\mathrm{PFC}^{3 \mathrm{D}}$; (b) calibrate a model micro property (bond stiffness) using compression tests of hemp stem; (c) simulate power requirement of hammermill and dynamic behaviours of hemp particles under different operating conditions of hammermill.

\section{METHODOLOGY}

\section{Simulated hemp}

Structure of simulated hemp A real hemp stem has a hollow structure, mainly consisting of a core surrounded by a thin layer of bast fibre (Fig. 1a). In constructing a simulated hemp stem, a set of $\mathrm{PFC}^{3 \mathrm{D}}$ basic particles (balls) connected with bonds were used using the $\mathrm{PFC}^{3 \mathrm{D}}$ cluster logic. Balls in the cluster were arranged as a hollow structure, as shown in Fig. 1b. The construction process starts with a circle of the desired diameter and then extends along the axial direction up to the desired length. The thickness of the stem was achieved by following the layers of balls along the circle. More layers increase the number of particles and the computational time. One layer is not enough to represent the fracture behaviour for the hemp 


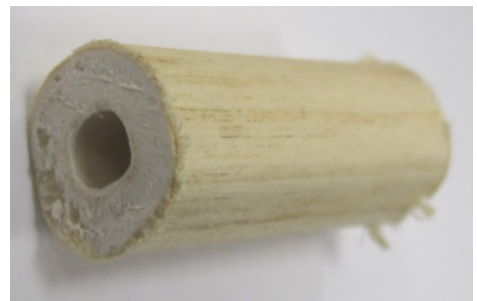

(a)

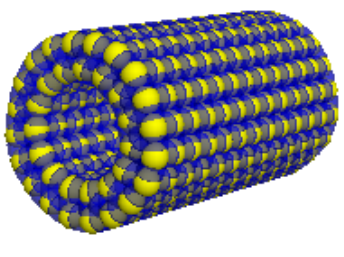

(b)
Fig. 1. Hemp stem; (a) Real, (b) Model.

core. For simplicity, two layers of balls were used for the simulated hemp stem to have sufficient structure for internal fracturing. As no reason to use different sizes of balls, all the balls in a simulated hemp stem had the same diameter that produced a uniform wall thickness.

By nature, hemp stalk is an anisotropic material. This is because of the internal construction of the cellulose. For the simplicity of the simulated hemp structure, it was assumed as isotropic material. Bonding is required among balls within the simulated hemp stalk to create an isotopic structure. The $\mathrm{PFC}^{\mathrm{BD}}$ Parallel-Bonds were installed between all balls which are in contact. The bonds connect balls over a circular cross-section lying on the contact plane between the balls. In $\mathrm{PFC}^{3 \mathrm{D}}$, a ball is considered a rigid body and cannot be broken (Itasca 2008). Thus, breaking the simulated hemp means breaking the bonds only.

Microproperties of simulated hemp In $\mathrm{PFC}^{3 \mathrm{D}}$, the simulated hemp described above is defined by a set of ball and bond microproperties. The ball microproperties include normal stiffness $\left(\mathrm{K}_{n}\right)$, shear stiffness $\left(\mathrm{K}_{s}\right)$, and friction coefficient $(\mu)$, and the bond microproperties include normal and shear stiffness $\left(\mathrm{k}_{\mathrm{nb}}\right.$ and $\left.\mathrm{k}_{\mathrm{sb}}\right)$, normal and shear strength $\left(\sigma_{c}\right.$ and $\left.\tau_{c}\right)$, and the bond-radius multiplier $(\lambda)$. The bond-radius multiplier is the ratio of the bond radius and ball radius. Calibrations of these microproperties are essential to simulate the behaviours of any material. However, only one of these parameters can be calibrated at one time. Others need to be determined based on the literature, theories, or assumptions.

Sadek et al. (2011) has calibrated the ball properties of hemp fibre and core. Their values for the core $\left(\mathrm{K}_{\mathrm{n}}=\mathrm{K}_{\mathrm{s}}=\right.$ $5 \times 10^{4} \mathrm{~N} \mathrm{~m}^{-1}$ and $\mu=1.0$ ) were used in this study to represent the ball microproperties of simulated hemp stem, as a hemp stem is mainly composed of the core. For bond microproperties, $\tau_{c}$ was set to be equal to $\sigma_{c}$ and $\mathrm{k}_{\mathrm{nb}}$ was set to be equal to $\mathrm{k}_{\mathrm{sb}}$ to reduce the number of unknowns. Similar assumptions have been made in the literature for modelling other materials (Asaf et al. 2007; McDowell and Harireche 2002). The value of $\lambda$ was set to be equal to one for the maximum contact areas between balls and bonds.

The bond stiffness $\mathrm{k}_{\mathrm{nb}}$ was determined based on its relationship with the ball stiffness, $\mathrm{K}_{\mathrm{n}}$. Potyondy and
Cundall (2004) described the relationship between stiffness and Young's modulus. For balls,

$\mathrm{K}_{\mathrm{n}}=4 \mathrm{RE}_{\mathrm{c}}$

where

$\mathrm{K}_{\mathrm{n}}=$ stiffness of the ball $\left(\mathrm{N} \mathrm{m}^{-1}\right)$,

$\mathrm{R}=$ radius of the ball $(\mathrm{m})$,

$\mathrm{E}_{\mathrm{c}}=$ Young's modulus of the ball $(\mathrm{Pa})$.

For bonds,

$$
\mathrm{k}_{\mathrm{nb}}=\frac{\mathrm{E}_{\mathrm{cb}}}{\mathrm{R}^{\mathrm{A}}+\mathrm{R}^{\mathrm{B}}}
$$

where

$\mathrm{k}_{\mathrm{nb}}=$ stiffness of the bond $\left(\mathrm{Pa} \mathrm{m}^{-1}\right)$,

$\mathrm{R}^{\mathrm{A}}$ and $\mathrm{R}^{\mathrm{B}}=$ the radius of two connecting balls $\mathrm{A}$ and $\mathrm{B}$, respectively (m),

$\mathrm{E}_{\mathrm{cb}}=$ Young's modulus of bond $(\mathrm{Pa})$.

Here the radius of the balls is known. Assuming $E_{c}=E_{c b}$ and using the value of $\mathrm{K}_{\mathrm{n}}$, the $\mathrm{k}_{\mathrm{nb}}$ can be determined. Thus, only the bond strength, $\sigma_{c}$ needs to be calibrated.

Calibration of the bond strength A compression test was conducted to calibrate the bond strength. In the hammermill, hemp stalks are under compressive forces. However, local stresses within a stalk could be tensile or compressive. Thus, the bonds among the balls could be under either tensile or compressive strength, and they could fail due to either stress. Hemp stalks are impacted in all directions by the hammers inside the hammermill; however, hemp stalk is weaker in lateral loading conditions (Khan et al. 2010). Thus, the lateral loading condition was used in the compressive test to calibrate the model parameter, with an assumption that bond strength was the same for all loading conditions/directions. Literature data are available for compression of hemp stems (Khan et al. 2010). Compression tests were conducted using $\mathrm{PFC}^{3 \mathrm{D}}$ to use those data for calibrations. The maximum breaking strength of hemp stem obtained from the simulation was compared with data from Khan et al. (2010) to calibrate the bond strength.

Source of the literature data for calibrations Data for calibrations were from compression tests of hemp stems conducted by Khan et al. (2010). In their tests, all specimens of hemp stem used were $25 \mathrm{~mm}$ long (Fig. 2a). A universal testing system (Fig. 2b) was used to compress the hemp specimens. As the compression rod of the testing system moved down, the hemp specimen was subjected to a vertical load. The force-displacement curve of the specimen was recorded until the specimen failed. The maximum compressive force was then identified from the recorded curve. A total of 240 specimens were tested by Khan et al. (2010). Those specimens had an average diameter and an average wall thickness of $10 \mathrm{~mm}$ and $4 \mathrm{~mm}$, respectively. The average maximum compressive force of those specimens was $93.67 \mathrm{~N}$. These average values were used in this study to calibrate the bond strength.

Compression test model development $\mathrm{A}$ compression test model was developed to simulate the compression tests conducted by Khan et al. (2010). A virtual platform was 

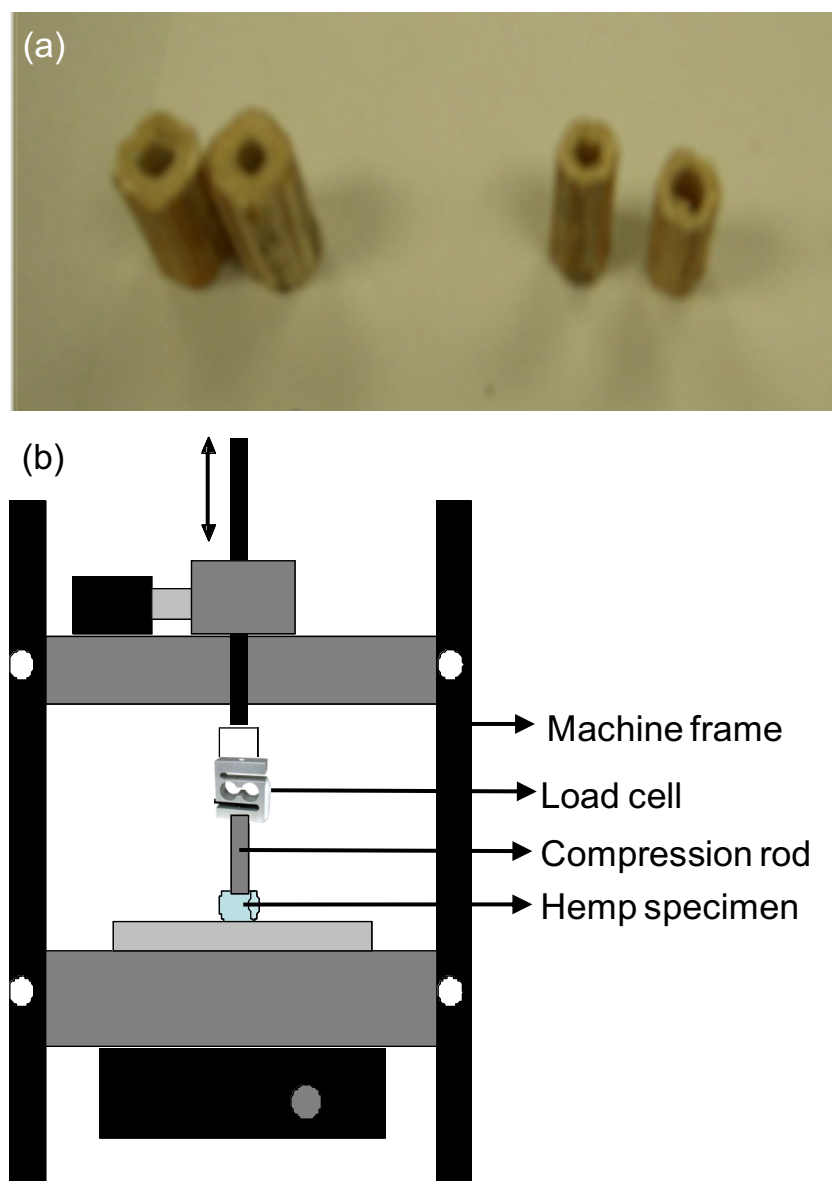

Fig. 2. Compression test of the hemp stem; (a) hemp specimens, (b) schematic of a universal testing system (Khan et al. 2010).

constructed using the $\mathrm{PFC}^{3 \mathrm{D}}$ wall commands to simulate the universal testing system shown in Fig. $2 b$. The platform consisted of a rectangular base and a compression rod (Fig. 3). A simulated hemp stem with a diameter of $10 \mathrm{~mm}$, a thickness of $4 \mathrm{~mm}$ (each ball with $2 \mathrm{~mm}$ diameter) and a length of $25 \mathrm{~mm}$ was placed on the top surface of the rectangular base. These dimensions were the same as the average dimensions of the specimens used by Khan et al. (2010). The bond stiffness was calculated as $2.5 \times 10^{9} \mathrm{~Pa} \mathrm{~m}^{-}$ ${ }^{1}$ using these dimensions based on Eqs. 1 and 2. Wall micro properties for compression rod and the rectangular base were used similar to the Sadek et al. (2011). Their values for the wall-normal and shear stiffness $K_{n w}=K_{s w}=5 \times 10^{4} \mathrm{~N}$ $\mathrm{m}^{-1}$ and friction, $\mu_{\mathrm{w}}=1.0$ were used. The centre of the simulated hemp stem was lined up with the centre of the compression rod. Therefore, the compression force was applied at the centre of the simulated hemp stem.

A constant downward velocity was applied to the compression rod to simulate the compression test. The compression rod moved down until the hemp stem failed,

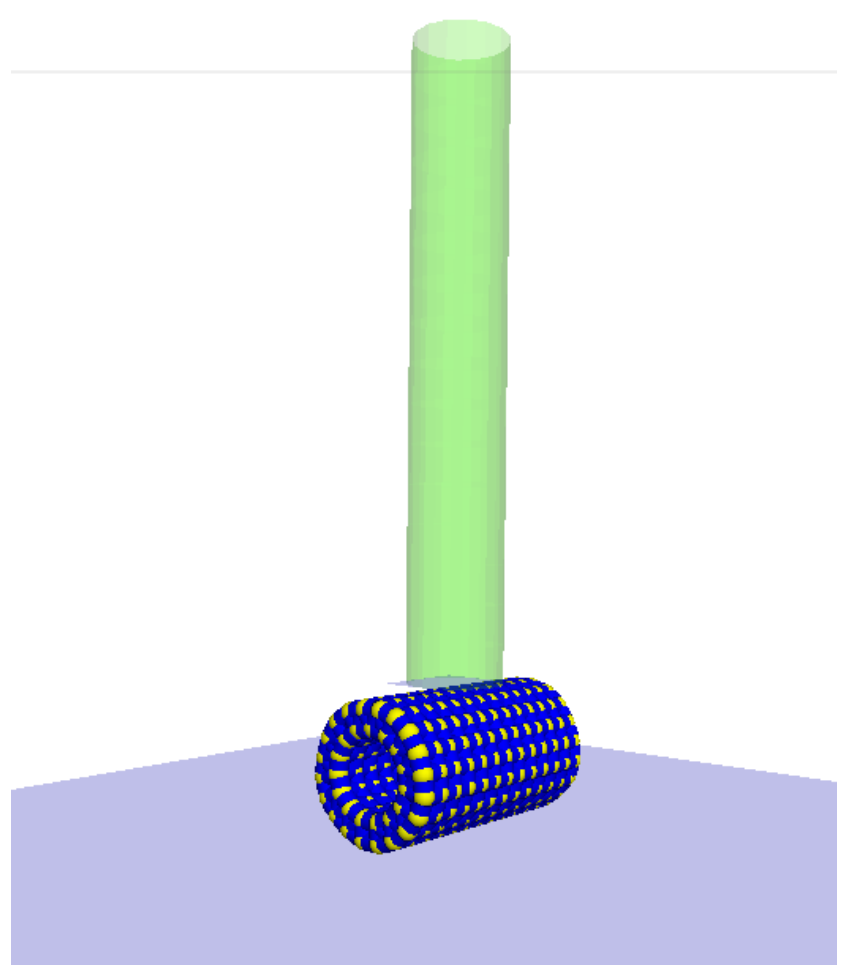

Fig. 3. Compression test model with the simulated platform and hemp stem.

reflected by the drop of the force. The total force acting on the compression rod was considered the compression force. The force-displacement of the rod was recorded during the virtual test. The maximum compression force was read from the first peak point of the force curve.

Hammermill model development The main components of a real hammermill typically include a drum, hammers mounted on the drum, and a housing that has a screen at the bottom. The drum and hammers rotate at high speed when the hammermill is in operation. The rotating hammers impact the hemp being fed into the housing. As a result, the hemp stalk is broken into pieces. Small pieces fall through the screen and are discharged into the "fine" stream or waste stream, and large pieces are collected as the main product. These main features of the hammermill were used to develop a simulated hammermill in this study. Micro properties for the wall were similar to the compression test. Hammermill and hemp stalk generation A hammermill model was developed in PFC $^{3 \mathrm{D}}$. The simulated hammermill consisted of a housing, a drum, six hammers, and a screen, simplified as $\mathrm{PFC}^{3 \mathrm{D}}$ walls and lines (Fig. 5). A cylindrical wall was placed at the centre to make the drum. Six hammers were made with three intersecting flat walls passing through the drum's centre. The hammers were surrounded by a cylindrical mesh functioning as a screen. The mesh was constructed by using numerous rings around the axis of the drum and numerous lines on the periphery of 


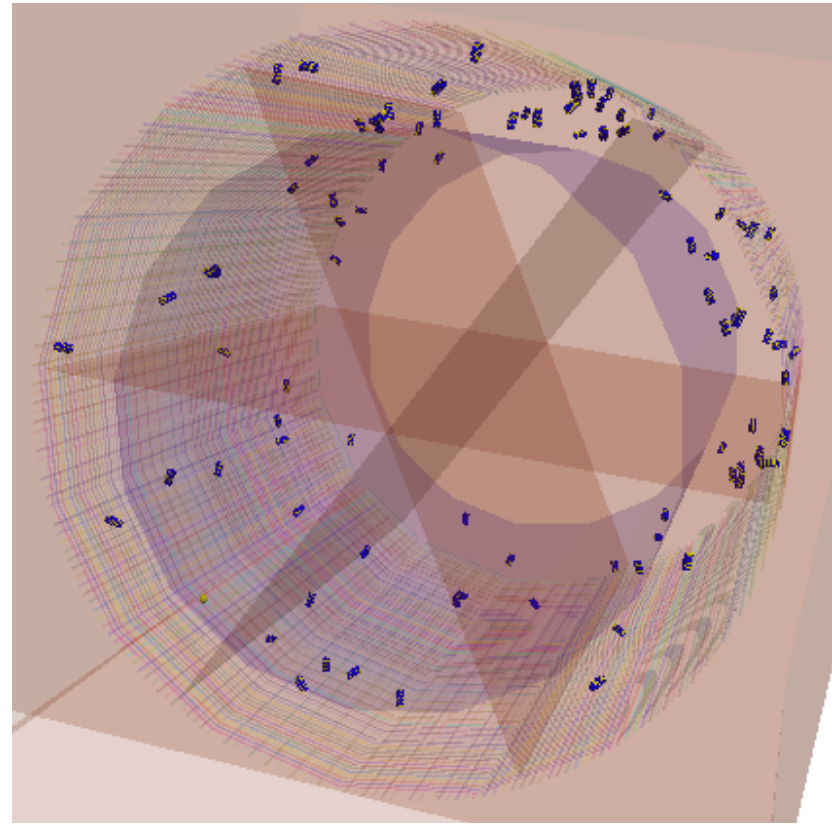

Fig. 4. Hemp segments generated in the hammermill model.

the rings along the axis of the drum. Both rings and lines were spaced $20 \mathrm{~mm}$ to obtain a mesh opening of $20 \mathrm{~mm}$. Then the whole assembly was fitted into box-shaped housing constructed using flat walls. The dimensions of the simulated hammermill were similar to the hammermill used by Baker (2009) for processing hemp. The diameter of the drum was $560 \mathrm{~mm}$. The three crossing walls extended 175 $\mathrm{mm}$ outside the drum, which was the effective hammer length.

In practice, before being fed to a hammermill, hemp stalk may be cut into segments, for example, $40 \mathrm{~mm}$ long segments (Baker 2009). Therefore, the simulated hemp segments of $40 \mathrm{~mm}$ length were fed into the hammermill. As PFC $^{3 \mathrm{D}}$ does not allow particle clusters like the simulated hemp stems defined above, the assembly of segments were generated in several steps. The first step was generating balls into the simulated hammermill. The second step was replacing the balls with clumps, which had the same shapes and dimensions as the simulated hemp segments. A clump in $\mathrm{PCF}^{3 \mathrm{D}}$ is a rigid body formed by a set of balls attached together, and forces cannot break it. The final step was converting the clumps to clusters by releasing the balls within the clump without changing the shapes and dimensions. Then the selected and calibrated micro properties were assigned to the particles and bonds. Figure 4 shows the hemp segment distribution in the simulated hammermill. The number of hemp segments is determined based on the feed mass desired.

Simulations of hammermill operation After generating (batch feed) the simulated hemp segments into the hammermill, the hammermill was assigned a rotational speed. The model allowed changing the operational parameters, including feed mass, rotational speed, and duration. The simulation will enable one to observe the dynamic behaviours of hemp particles while being processed in the hammermill. In this study, the dynamic attributes of interest included the power requirement of the hammermill and the particle kinetic and strain energies. These attributes were recorded using the $\mathrm{PFC}^{3 \mathrm{D}}$ history command during the simulations.

The total kinetic energy of particles is the energy of all balls accounting for both translational and rotational motions. Total kinetic energy is expressed as (Itasca 2008)

$\mathrm{E}_{\mathrm{k}}=\frac{1}{2} \sum_{\mathrm{N}_{\mathrm{b}}}\left(\mathrm{m}_{\mathrm{i}} \mathrm{V}_{\mathrm{i}}^{2}+\mathrm{I}_{\mathrm{i}} \omega_{\mathrm{i}}^{2}\right)$

where

$E_{k}=$ kinetic energy $(\mathrm{J})$,

$\mathrm{N}_{\mathrm{b}}=$ the number of balls,

$\mathrm{m}_{\mathrm{i}}=$ inertial mass of $\mathrm{i}^{\text {th }}$ body $(\mathrm{kg})$,

$\mathrm{I}_{\mathrm{i}}=$ inertia tensor of $\mathrm{i}^{\text {th }}$ body $\left(\mathrm{kg} \mathrm{m}^{2}\right)$,

$\mathrm{V}_{\mathrm{i}}=$ translational velocities of $\mathrm{i}^{\text {th }}$ body $\left(\mathrm{m} \mathrm{s}^{-1}\right)$,

$\omega_{i}=$ rotational velocities of $\mathrm{i}^{\text {th }}$ body $\left(\operatorname{Radian} \mathrm{s}^{-1}\right)$.

Total strain energy is the energy of the entire assembly stored at all contacts. Total strain energy is expressed by (Itasca 2008)

$\mathrm{E}_{\mathrm{k}}=\frac{1}{2} \sum_{\mathrm{N}_{\mathrm{c}}}\left(\left|\mathrm{F}_{\mathrm{i}}^{\mathrm{n}}\right|^{2} / \mathrm{k}_{\mathrm{nb}}+\left|\mathrm{F}_{\mathrm{i}}^{\mathrm{s}}\right|^{2} / \mathrm{k}_{\mathrm{sb}}\right)$

where

$E_{\mathrm{s}}=$ strain energy $(\mathrm{J})$,

$\mathrm{N}_{\mathrm{c}}=$ number of contacts,

$\left|\mathrm{F}_{i}^{\mathrm{n}}\right|=$ magnitudes of the normal components of the $\mathrm{i}^{\text {th }}$ contact force $(\mathrm{N})$,

$\left|\mathrm{F}_{i}^{\mathrm{s}}\right|=$ magnitudes of the shear components of the $\mathrm{i}^{\text {th }}$ contact force $(\mathrm{N})$,

$\mathrm{k}_{\mathrm{nb}}=$ bond normal stiffness $\left(\mathrm{Pa} \mathrm{m}^{-1}\right)$,

$\mathrm{k}_{\mathrm{sb}}=$ bond shear stiffness $\left(\mathrm{Pa} \mathrm{m}^{-1}\right)$.

Energy consumption of the simulated hammermill was determined from work done by all moments and forces arising from all particles in contact with the hammers. Power was calculated from the corresponding kinetic strain and energies on each simulated hammer using Eq. 5. The average power of the six individual hammers was considered the total simulated hammermill power. This calculated power is equivalent to the power used by the actual hammermill.

$$
P=\sum \frac{E_{k}+E_{S}}{t}
$$

where

$\mathrm{P}=$ power (watt),

$E_{k}=$ kinetic energy $(\mathrm{J})$,

$E_{s}=$ strain energy $(J)$,

$\mathrm{t}=$ time (s). 


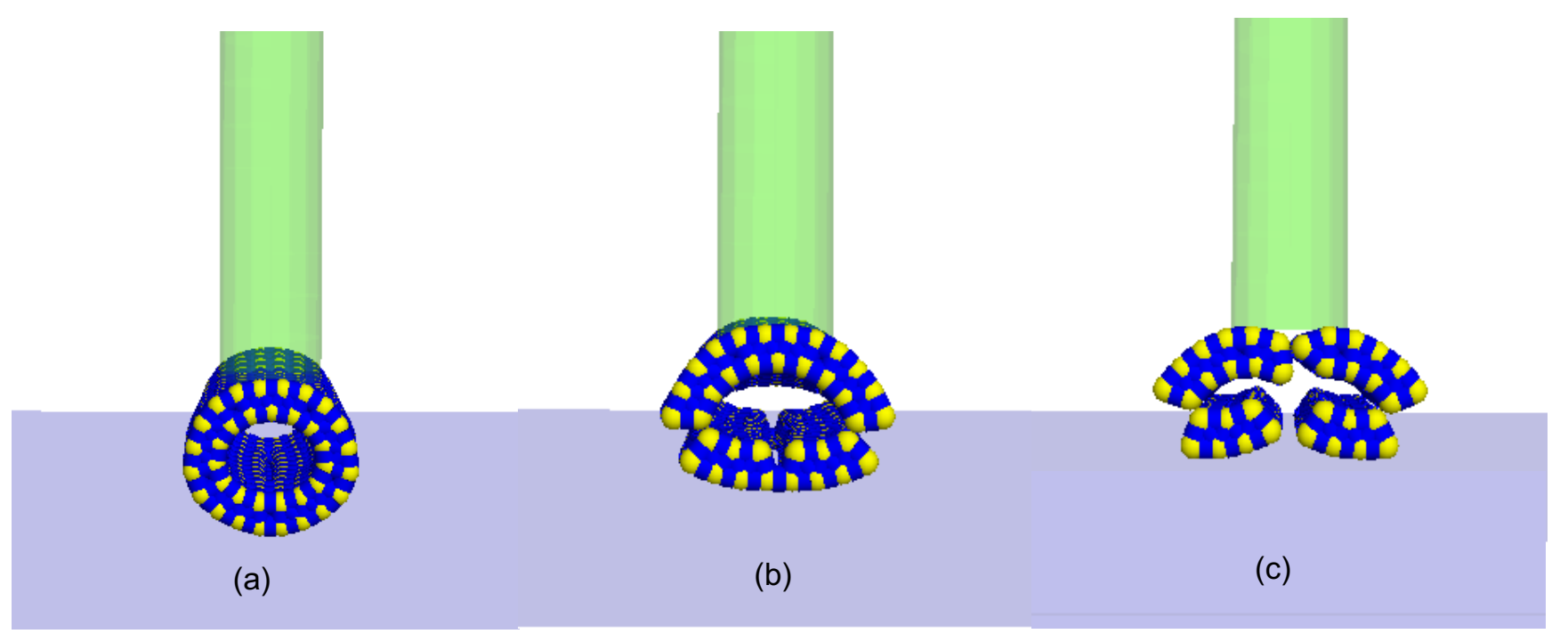

Fig. 5. Breaking steps of hemp specimen during a simulated compression test.

\section{RESULTS AND DISCUSSION}

\section{Calibration results}

Compression behaviour of hemp The simulated compression tests using the constructed compression platform (Fig. 5a) showed that breakage of the specimen occurred at the bonds, and fracturing of the specimen followed several steps. At the very beginning of the compression, fracturing occurred near the contact point between the specimen and the base of the compression platform, followed by fracturing on the sides of the specimen, resulting in the specimen being broken into three pieces (Fig. 5b). Finally, fractures were developed near the contact point between the specimen and the compression rod, resulting in the specimen being broken into four pieces (Fig. 5c).

A typical force-time curve from the simulated compression test is shown in Fig. 6. The curve matches the breakage phenomenon shown in Fig. 5 (Khan et al., 2010). When the hemp specimen was compressed, the force increased in a nearly linear fashion; at a certain point, the force reached its peak; then fracturing started within the structure of the specimen. The fluctuating part of the curve represents the several steps of the fracturing process. When the entire specimen collapsed, the force dropped completely.

Calibrated micro properties The results from the simulated compression tests were used to calibrate the bond strength of the particles. While keeping the other microproperties constant, the bond strength value was varied in the simulations. For each assumed bond strength, the test gave a force-time curve where the maximum force was read and listed in Table 5.1. Then the relative error between each simulated maximum force and the force $(93.67 \mathrm{~N})$ measured by Khan et al. (2010) was determined using the following equation:

$$
\mathrm{RE}=\frac{\left(\mathrm{f}_{\mathrm{m}}-\mathrm{f}_{\mathrm{s}}\right) \times 100}{\mathrm{f}_{\mathrm{m}}}
$$

where

$\mathrm{RE}=$ relative error,

$\mathrm{f}_{\mathrm{m}}=$ measured maximum force $(\mathrm{N})$,

$\mathrm{f}_{\mathrm{s}}=$ simulated maximum force $(\mathrm{N})$.

The relative errors for various assumed bond strengths are listed in Table 1. The best match between the simulated and measured maximum forces was when the bond strength was $2.2 \times 10^{6} \mathrm{~Pa}$, giving the least relative error: $0.54 \%$. This calibrated bond strength value was used to simulate hemp processing discussed below.

\section{Hammermill simulation results}

The calibrated model predicted the hemp particles' dynamic behaviours in the hammermill. It should be noted that the model was calibrated only for compressive forces applied in the lateral direction of hemp stalks and might not be valid for the longitudinal loadings. The hammermill was operated under three different feed masses and three rotational speeds. The power requirement of the hammermill the kinetic and strain energies of hemp particles were recorded for each condition.

Failure patterns of particles After being impacted by the rotating hammers, the hollow structure of the hemp segments were broken into clusters of balls. Those clusters had various sizes, depending on the rotational speed of the hammers. The size reduction of the hemp stalks was evaluated qualitatively based on the number of particles present on the broken hemp stalk. It was observed that the overall cluster sizes were smaller, i.e., containing a smaller number of balls per cluster, at a higher rotational speed (Fig. 7c), compared to a lower rotational speed (Figs. 7a, b). With the $1000 \mathrm{rpm}$ speed, most hemp segments were broken along the axial direction, i.e., the most broken pieces kept the whole length of the original hemp segments (Fig. 7a). With the $2000 \mathrm{rpm}$ speed, breakage occurred along both axial and radial directions, forming smaller and shorter pieces (Fig. 7b). Even smaller and shorter pieces were 


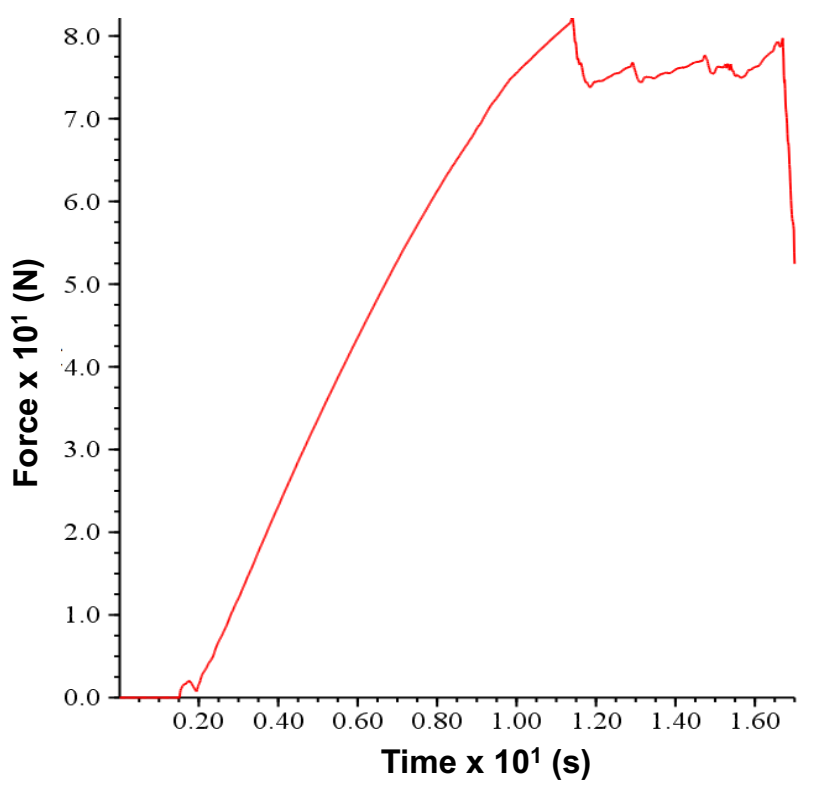

Fig. 6. Typical force-time curve obtained in a simulated compression test. $(1$ second $=1000$-time step $)$.

observed at $3000 \mathrm{rpm}$ (Fig. 7c). It should be noted that this observation was based on the assumption that the simulated hemp stalks were isotropic, and bond strength was assumed the same in all directions. At the same time, it is a known fact that hemp stalks are more robust in the longitudinal direction than the lateral direction.

Power requirement of hammermill Figure 8 shows that the power requirement of the hammermill highly fluctuated over time, represented by numerous peaks. After the hammers were given a rotational speed, the magnitude of the power increased rapidly to the maximum value. At that time, the hammers reached their constant speed and hit many unbroken hemp segments, and therefore the highest power peak was observed. In some observations, the power
Table 1. Summary of calibration results.

\begin{tabular}{ccc}
\hline $\begin{array}{c}\text { Assumed bond } \\
\text { Strength }(\mathrm{Pa})\end{array}$ & $\begin{array}{c}\text { Simulated } \\
\text { max. force }(\mathrm{N})\end{array}$ & $\begin{array}{c}\text { Relative } \\
\text { Error }(\%)\end{array}$ \\
\hline $2.0 \times 10^{6}$ & 84.65 & 9.63 \\
$2.2 \times 10^{6}$ & 93.16 & 0.54 \\
$2.5 \times 10^{6}$ & 107.59 & 14.86 \\
$3.0 \times 10^{6}$ & 129.35 & 38.09 \\
$4.0 \times 10^{6}$ & 352.47 & 275.79 \\
\hline
\end{tabular}

peak did not occur initially because the hammer had not been in contact with a large volume of particles immediately after starting rotating. While continuously impacting the hammers, hemp pieces became smaller and smaller. Some of those tiny pieces fell through the screen, resulting in fewer particles in the hammermill housing. As a result, fewer particles were in contact with the hammers, the magnitudes of those peak powers were being reduced.

The maximum power was recorded for each feeding rate: 80,130 , and $260 \mathrm{~g}$. The results showed that the power requirement increased with the increase of feed mass, especially at a higher rotational speed (Fig. 9). The power requirement also increased with the increase of the rotational speed. The maximum power for different feed masses ranged from 4.52-6.54 kW, 9.32-17.72 kW, 14.05$23.48 \mathrm{~kW}, 14.85-24.12 \mathrm{~kW}$ and $22.6-30.1 \mathrm{~kW}$ for 1000 , 1500, 2000, 2500 and $3000 \mathrm{rpm}$, respectively. The power requirements for the 2000 and $2500 \mathrm{rpm}$ were close at all the feed masses. However, for the $3000 \mathrm{rpm}$, the power requirements were much higher, regardless of the feeding mass. The average power over all scenarios was $13.57 \mathrm{~kW}$. The current model overestimated the power requirement compared to the power requirement $(14.25 \mathrm{~kW})$ reported by Baker (2009) for processing hemp with hammers rotating at $3600 \mathrm{rpm}$. This was because the model calculated the power required by every particle in motion inside the hammermill. In contrast, the power consumption in existing systems is related to the hemp stalks subjected to loading.

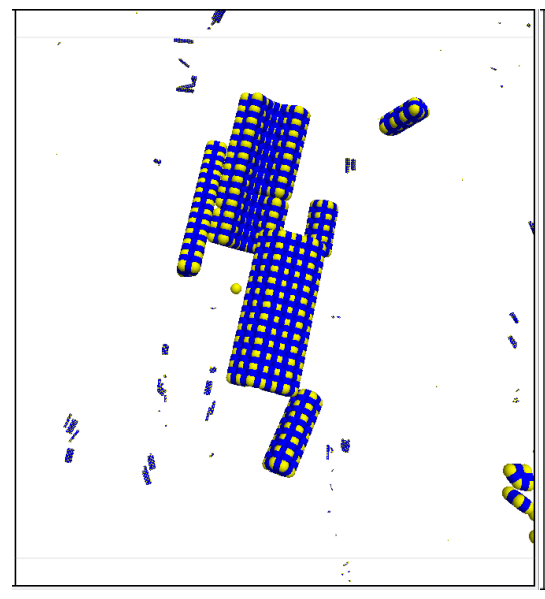

(a)

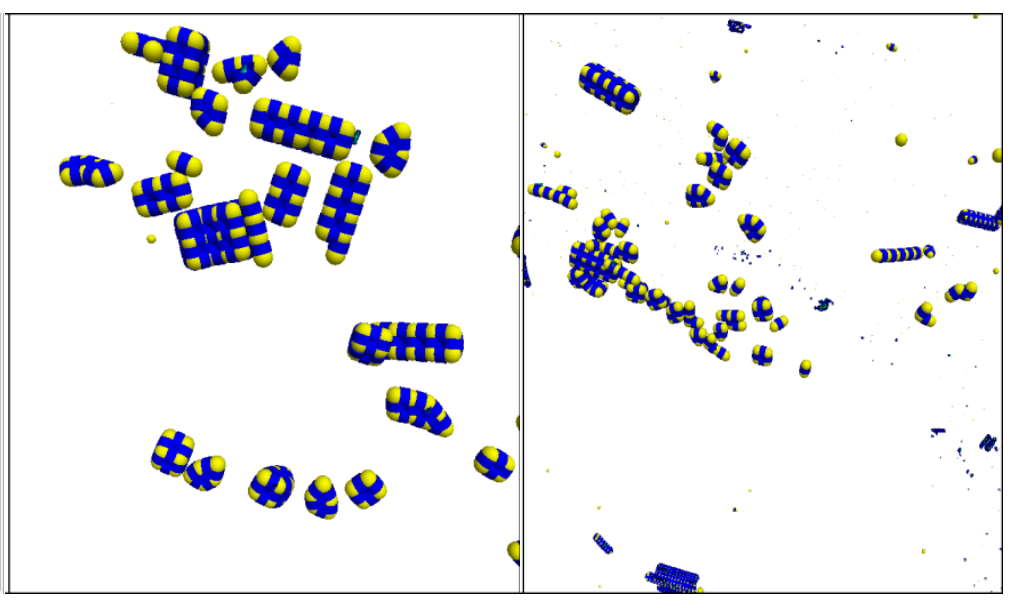

(b) (c)

Fig. 7. Screenshots of hemp particles impacted by the hammers at different rotational speeds (pictures are not to scale); (a) $1000 \mathrm{rpm}$, (b) $2000 \mathrm{rpm}$, and (c) $3000 \mathrm{rpm}$. 


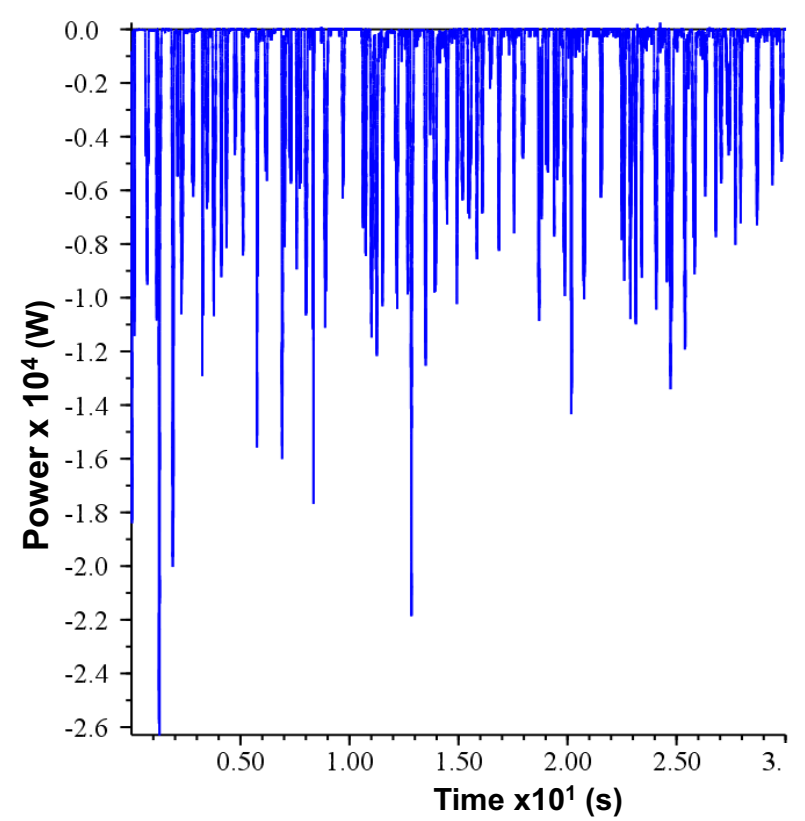

Fig. 8. Typical model output for time $(1$ second $=1000$ time step) vs power of hammermill.

Kinetic energy of hemp particles As the hammers started rotating, the kinetic energy of hemp particles increased rapidly. Within a very short time, it reached its peak value. Then it decreased by approximately $50 \%$, where the kinetic energy fluctuated less and became relatively steady (Fig. 10). These reflected the different stages of hemp processing. The kinetic energy increases at the beginning represented the stage of accelerating of hemp particles as the hammer rotational speed increased. The peak kinetic energy implied that the maximum rotation speed of the hammers had been reached, and hemp particles fed in the hammermill housing were in full motion. The following decreasing power meant that the hemp segments were being broken into pieces, and some of those pieces were falling through the screen while the hammers rotated. Therefore, fewer numbers of particles in the hammermill housing contributed to the total kinetic energy.

The maximum kinetic energy was read from the energytime curve shown in Fig. 10 for each simulation. The values of the maximum kinetic energy were then converted to the specific kinetic energies, expressed as the energy per unit mass of hemp material fed in the hammermill. The results showed that the overall specific kinetic energy ranged from 0.09 to $2.14 \mathrm{~kW} \mathrm{hr} \mathrm{t}^{-1}$ for all feed masses and rotational speeds (Fig. 11). The specific energy increased with the increase of the feed mass. The lower rotational speed generally resulted in lower specific kinetic energy at the same feed mass. This could be explained by the fact that hemp stems were broken into smaller pieces at higher rotational speed; those small pieces passed through screen openings and did not contribute to the kinetic energy.

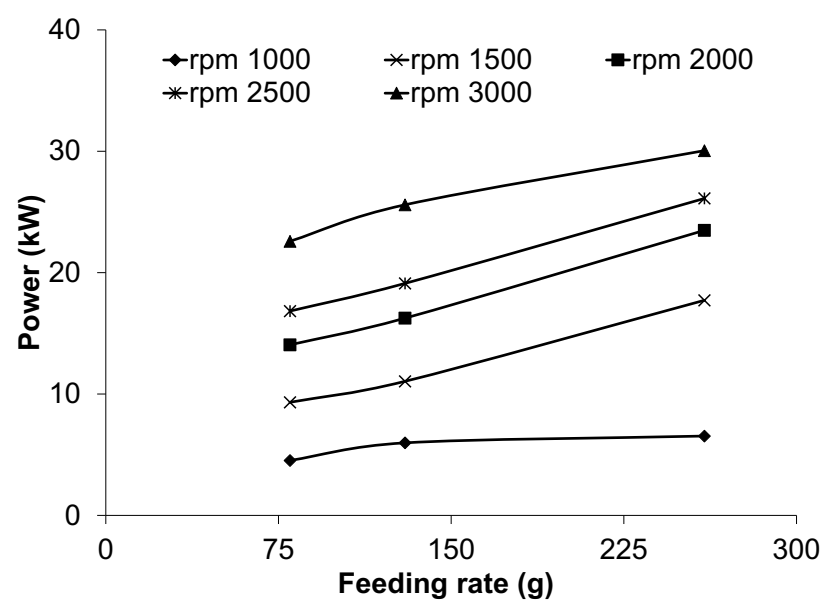

Fig. 9. Maximum power of the hammermill as affected by the feeding mass.

The strain energy of hemp particles Strains energy develops within the contacts of particles. The simulated strain energy was initially highest and decreased over time (Fig. 12). Before hemp segments were broken inside the hammermill, more hemp particles were in contact within the clusters, and therefore the total strain energy was higher. More hemp segments were being broken with time, meaning the breakage of more bonds between particles within the clusters. Therefore, there would be fewer and fewer contacts among the particles. This explains the reduced trend of the total strain energy over time. Near the end of the simulation, the strain energy fluctuated around a constant value, indicating that the remaining bonds between hemp particles were not further broken.

Depending on the feed masse and rotational speed, the specific strain energy ranged from 1.93 to $8.68 \mathrm{~kW} \mathrm{hr} \mathrm{t}^{-1}$. Under each speed, the specific strain energy was linearly increased with the increase of the feed mass (Fig. 13). Interestingly, the values of specific strain energy of 1500 , 2000 and $3000 \mathrm{rpm}$ were lower than that of the $1000 \mathrm{rpm}$ at the same feed mass. This phenomenon could be attributable to the different failure patterns of the hemp clusters to varying speeds, as shown in Fig. 7. The strain energy was not only related to the number of particles that are in contact but also related to the orientation of the particles. A cluster with the same number of particles could have different particle orientations and, therefore, different contacts. Figure 14 illustrates that a four-particle cluster can have three contacts (Fig. 14a), four contacts (Fig. 14b), or six contacts (Fig. 14c), depending on the particle orientation. All contacts in Figs. 14a and 14b are within the same plane, while contacts in Fig. 14c are in different planes. It was speculated that the contacts of the particles for 1500,2000 and $2500 \mathrm{rpm}$ might be more like those shown in Figs. 14a and $14 \mathrm{~b}$. As a result, the specific strain energies were low at this speed. 


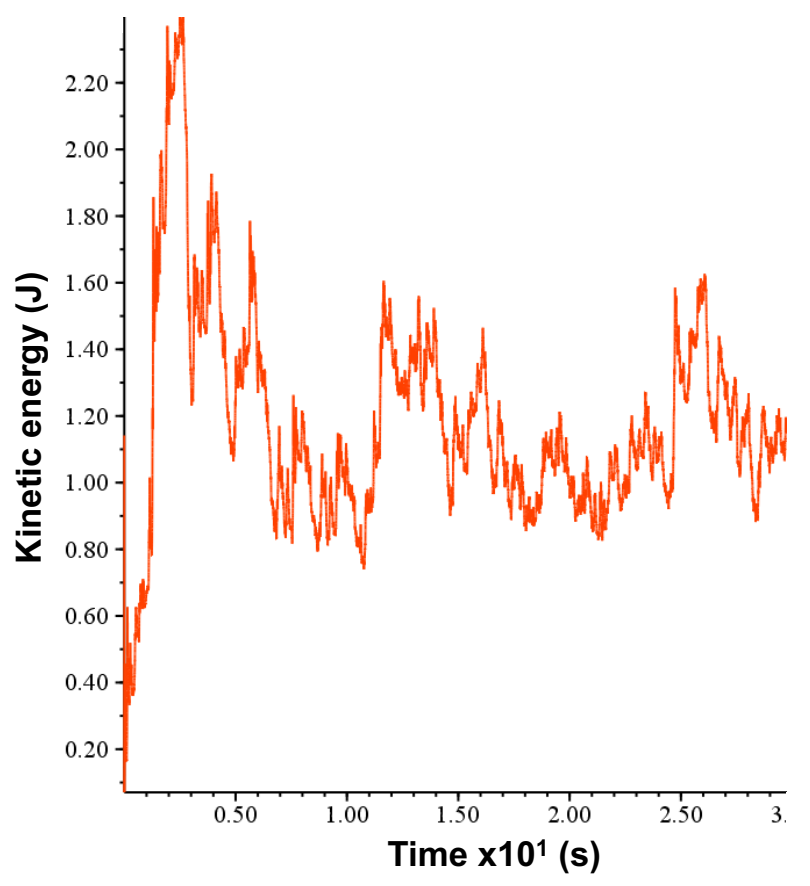

Fig. 10. Typical model output of kinetic energy (1 second $=1000$-time step) vs time.

\section{CONCLUSIONS}

A discrete element model was developed to simulate hemp fibre processing in a hammermill using $\mathrm{PFC}^{3 \mathrm{D}}$. A simulated hemp stem could be formed using a cluster of balls and bonds in the model. Calibration of particle bond stiffness was achieved using a compression test simulation. The calibrated bond stiffness of hemp stem was $2.2 \times 10^{6} \mathrm{~Pa}$ with a relative error of $0.54 \%$ compared to the literature data of hemp compression tests. The model overestimated the power requirement compared to the literature data. Kinetic and strain energy inside the hammermill under different feeding masses and hammer rotational speeds were observed. The predicted values varied from 4.52 to 30.05 $\mathrm{kW}$ for the power requirement, from 0.09 to $2.14 \mathrm{~kW} \mathrm{hr} \mathrm{t}^{-1}$

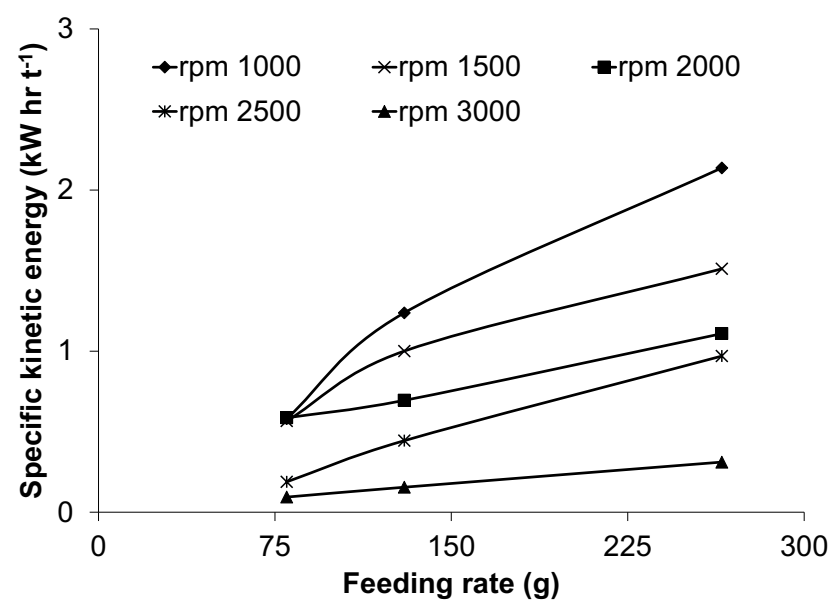

Fig. 11. The specific kinetic energy of the hammermill as affected by the feed mass.

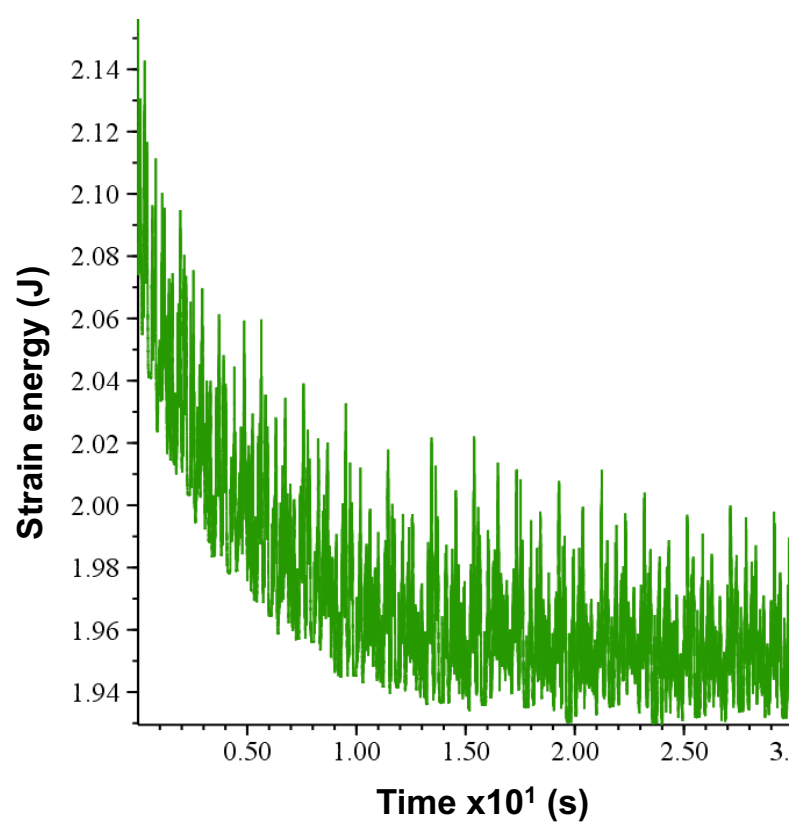

Fig. 12. Typical model output of strain energy (1 second $=1000$-time step) vs time.

for the specific kinetic energy, and from 1.93 to $8.68 \mathrm{~kW} \mathrm{hr}$ $\mathrm{t}^{-1}$ for the specific strain energy, depending on the feed masse and rotational speed. In general, all these predicted variables were greater at higher feed mass, with the specific strain energy being the most sensitive variable to the feed mass. As for the effects of hammer rotational speed, an increasing trend was observed for the power requirement, a decreasing trend was observed for the specific kinetic energy, and a mixed result was observed for the specific strain energy. Given the following observations: the much greater power requirement at the $3000 \mathrm{rpm}$ than at the 2000 $\mathrm{rpm}$, the decreasing trend of the kinetic energy, and the lowest strain energy at the $2000 \mathrm{rpm}$, it is recommended to operate the hammermill at 2000 to $2500 \mathrm{rpm}$.

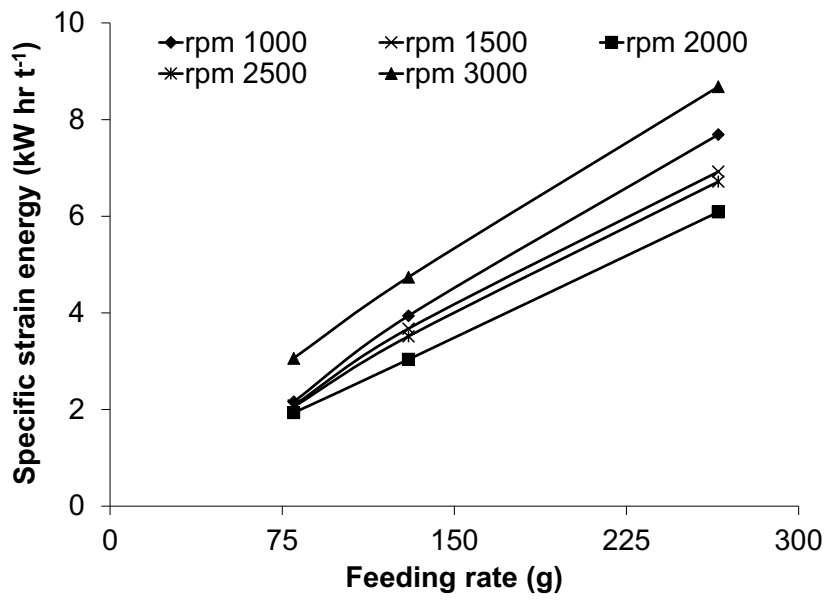

Fig. 13. The specific strain energy of particles as affected by the feed mass. 


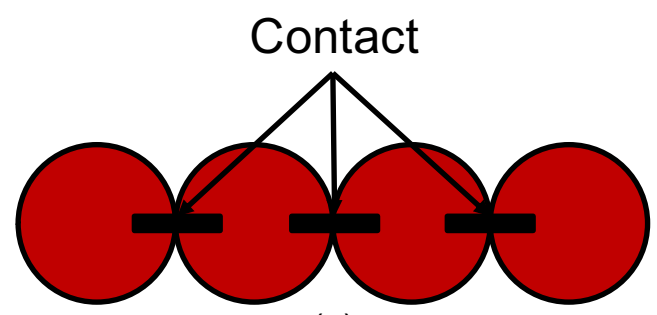

(a)

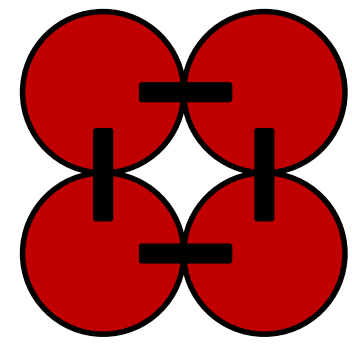

(b)

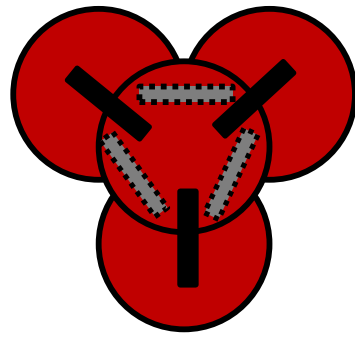

(c)

Fig. 14. Number of contacts for different particle orientations in a four-particle cluster.

\section{ACKNOWLEDGEMENT}

The research was supported by Natural Sciences and Engineering Research Council of Canada (NSERC).

\section{REFERENCES}

Asaf, Z., D. Rubinstein and I. Shmulevich. 2007. Determination of discrete element model parameters required for soil tillage. Soil \& Tillage Research 92(2): 227-242. https://doi.org/10.1016/j.still.2006.03.006

Baker, M. 2009. Evaluation of hammermill and planetary ball mill for hemp fibre decortications. Unpublished M.Sc. Thesis. Winnipeg, MB: Department of Biosystems Engineering, University of Manitoba.

Cleary, P.W. 1998. Predicting charge motion, power draw, segregation, and wear and particle breakage in ball mills using discrete element methods. Mineral Engineering 11(11): 1061-1080. https://doi.org/10.1016/S08926875(98)00093-4

Cleary, P.W. and D. Hoyer. 2000. Centrifugal mill charge motion and power draw: comparison of DEM predictions with experiment. International Journal of Mineral Processing 59: 131-148.

https://doi.org/10.1016/S0301-7516(99)00063-0

Coetzee, C.J. and D.N.J. Els. 2009. Calibration of discrete element parameters and the modelling of silo discharge and bucket filling. Computers and Electronics in Agriculture 65: 198-212.

https://doi.org/10.1016/j.compag.2008.10.002

Cundall, P.A. and O.D.L. Strack. 1979. A discrete numerical model for granular assemblies. Geotechnique 29: 47-65. https://doi.org/10.1680/geot.1979.29.1.47

Djordjevic, N. 2003. Discrete element modelling of the influence of lifters on powder draw of tumbling mills. Minerals Engineering 16: 331-336. https://doi.org/10.1016/S0892-6875(03)00019-0

Djordjevic, N., F.N. Shi and R.D. Morrison. 2003. Applying discrete element modelling to vertical and horizontal shaft impact crushers. Minerals Engineering 16: 983-991.

https://doi.org/10.1016/j.mineng.2003.08.007
Franco, Y., D. Rubinstein and I. Shmulevich. 2007. Prediction of soil-bulldozer blade interaction using discrete element method. Transactions of the ASABE 50(2): 345-353. https://doi.org/10.13031/2013.22625

Guzman, L. Y. Chen, M. Khan and S. Potter. 2015. Application of PFC3D to simulate a planetary ball mill. Agricultural Engineering International: CIGR Journal 17(4): 235-246.

Inoue, T. and K. Okaya, 1996. Grinding mechanism of centrifugal mills - a simulation study based on the discrete element method. International Journal of Mineral Processing 44-45: 425-435. https://doi.org/10.1016/0301-7516(95)00049-6

Itasca, 2008. PFC3D, Particle Flow Code in 3 Dimensions, Theory and Background. Itasca Consulting Group, Inc. Minneapolis, Minnesota, USA.

Khan, M.R., Y. Chen, C. Lague, H. Landry, Q. Peng and W. Zhong. 2010. Compressive properties of Hemp (Cannabis sativa L.) stalks. Biosystems Engineering 106: $\quad 315 \quad$ - 323. https://doi.org/10.1016/j.biosystemseng.2010.04.004

Lopo, P. 2002. The right grinding solution for you: roll, horizontal or vertical. Feed Management 53(3): 23-26.

Mani, S., L.G. Tabil and S. Sokhansanj. 2004. Grinding performance and physical properties of wheat and barley straws, corn stover and switchgrass. Biomass and

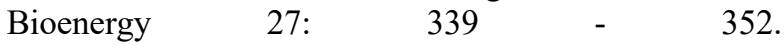
https://doi.org/10.1016/j.biombioe.2004.03.007

McDowell, G.R. and O. Harireche. 2002. Discrete element modelling of yielding and normal compression of sand. Géotechnique 52(4): 299-304. https://doi.org/10.1680/geot.2002.52.4.299

Miao, Z., T.E. Grift, A.C. Hansena and K.C. Ting. 2011. Energy requirement for comminution of biomass in relation to particle physical properties. Industrial Crops and Products 33: 504-513. https://doi.org/10.1016/j.indcrop.2010.12.016

Mishra, B.K. and C.V.R. Murty. 2001. On the determination of contact parameters for realistic DEM simulations of ball mills. Powder Technology 115: 290297. https://doi.org/10.1016/S0032-5910(00)00347-8 
Potyondy, D.O. and P.A. Cundall. 2004. A bonded-particle model for rock. International Journal of Rock Mechanics and Mining Sciences 41(8): 1329-1364. https://doi.org/10.1016/j.ijrmms.2004.09.011

Rajamani, R.K., B.K. Mishra, R. Venugopal and A. Datta. 2000. Discrete element analysis of tumbling mills. Powder Technology 109: 105-112. https://doi.org/10.1016/S0032-5910(99)00230-2

Sadek, M. A., Y. Chen, C. Lague, H. Landry, Q. Peng and W. Zhong. 2011. Characterization of the shear properties of hemp using discrete element method. Transaction of the ASABE 54(6): 2279-2285. https://doi.org/10.13031/2013.40641

Savoie, P., D. Trebly, R. Theriault, J.M. Wauthy and C. Vigneault. 1989. Forage chopping energy vs. length of cut. Transactions of the ASAE 32(2): 437-442. https://doi.org/10.13031/2013.31022
Shi, F., T. Kojovic, J.S. Esterle and D. David. 2003. An energy-based model for swing hammermills. International Journal of Mineral Processing 71: 147166. https://doi.org/10.1016/S0301-7516(03)00035-8

van Nierop, M.A., G. Glover, A.L. Hinde and M.H. Moys. 2001. A discrete element method investigation of the charge motion and power draw of an experimental twodimensional mill. International Journal of Mineral Processing 61: 77-92. https://doi.org/10.1016/S03017516(00)00028-4

Vigneault, C.T., T.M. Rothwell and G. Bougeois. 1992. Hammermill grinding rate and energy requirement for thin and conventional hammers. Canadian Agricultural Engineering 34(2): 203-206.

Yu, M., A.R. Womac, P.I. Miu, C. Igathinathane, S. Sokhansanj and S. Narayan. 2006. Direct Energy Measurement Systems for Rotary Biomass Grinder Hammermill. ASABE Paper no. 066217. St. Joseph, MI: USA. 